\title{
Word of Mouth, Viral Marketing and Open Data: A Large-Scale Simulation for Predicting Opinion Diffusion on Ethical Food Consumption
}

\author{
${ }^{1}$ Simulation Team, DIME University of Cenova, Genova, Italy, E-mail: agostino@simulationteam.com, \\ matteo.agresta@simulationteam.com \\ ${ }^{2}$ Department of Strategic Management and Marketing, De Montfort Universities, Leicester, UK, E-mail: jen.hsu@dmu.ac.uk
}

\begin{abstract}
:
This paper presents the first results of a large-scale-Agent-Based Simulation devoted to simulate individual behaviour inside a medium sized city (600,000 inhabitants). Humans are simulated as Intelligent Individual entities characterized by several attributes created from the Open Data available by means of a multi-layer approach. The work presented is divided into two main parts: the first part aims to describe the multi-layer approach adopted with the inclusion of the social network layer devoted to capture how social networks can be correlated with human activities and how an "Individual Opinion" can changes based on social interactions. The second part is devoted to present a preliminary case study for simulating the propagation dynamics of the individual opinion in the form of an ethical value function. The basic idea is to capture the changes in the individual opinion based on the social interactions predicted by the simulation. Finally, a food choice model for predicting individual choices based on the individual opinion function is presented; the model is based on three parameters: accessibility of ethical shops, price difference with standard products, and ethical value propagation.
\end{abstract}

Keywords: agent-based simulation, green products consumption simulation, social networks simulation, opinion simulation

DOI: 10.1515/ijfe-2018-0139

Received: May 2, 2018; Revised: December 20, 2018; Accepted: March 27, 2019

\section{Introduction}

The web of global economic connection is growing deeper [1] and the number of web-connected population is rising fast, in particular in emerging countries. It is interesting to note that mobile Industry declared that in 2017 number of people connected to mobile services surpassed 5 billion globally [2]. Several authors use the world "Digital Globalization" that underlines the new step of the globalization era that is moving from the globalization of "goods" up to the globalization of human digital connections. Web-Connected-Social-Systems represent the whole neural network of human kind where each single individual can represent a web interactive neuron of the global brain. For example, a recent research [3], proved that in 20,015 nearly $65 \%$ of American adults was using social networking sites while 10 years before, in 2005, the media usage was only at $7 \%$. In addition, it is important to consider how much time is spent on the web: indeed, according to recent surveys, $51 \%$ of US adults spent in average 5,6 h connected by Smartphone, laptop and other Internet services [4]: humans are constantly (at least potentially) connected to the web! This process led to radical changes in modern societies in a very quick time since social interactions have become easier, faster and more frequent by means of the Internet and the smartphones. Indeed, each individual with an Internet access is continuously bombarded by several information from friends, media, social networks and web advertising that can influence his opinion and mental status. In addition, each individual is both an emitter and a receiver node at the same time; indeed, he does not limit to receive but he can also publish information, pictures, tweets, posts that can potentially influence the other nodes. Such process generates viral loops of reading and publishing the most popular web content [5].

Reproducing the information exchange within a web connected network and its effect for each individual can be extremely interesting in many areas like Social Engineering, Viral Marketing, Social Science, Transport, Government and Politics as well as Safety and (Cyber) Security. A quantitative analysis of propagation phenomena is pretty challenging due to many factors: the first problem is the huge quantity of data that are needed, 
and the second one is the complexity of the human behaviour at the different levels: single entity (individual), system of entities (societies) as well as web-connected system of entities (World Wide Web). Due to such challenges, a Modelling \& Simulation $(M \& S)$ approach can be one of the key to provide quantitative results and a test environment for complex environment like web-based-social interactions, where only few, or partial data are available but a quantitative analysis is needed [6]. Indeed, the basic idea of the author is to reproduce quasirealistic individual based on available data and recreate virtually inside a simulator the connections among them, in order to find a way to evaluate the propagation dynamic of an hypothetical opinion function based on the world-of-mouth (WOM) phenomena.

The aim of this paper is twofold: the first goal is to describe a multi-layer simulation devoted to recreate individual behaviour in urban context with the use of the open data. The second is to define and test an "Opinion Function" in the marketing domain in the form of "Ethical Value" for capturing the individual behaviour on ethical food choices. Such function is incorporated into a binary choice model with two possible options: (a) buy standard food and (b) buy ethical food. The choice is assumed to be driven by the following three parameters: Price, Accessibility and Ethical Value.

\section{The word-of-mouth (WOM) phenomena}

The propagation phenomena in a social network, based on "physical interactions" were studied at first in medicine for analysing and predicting the dynamics of an epidemic evolution of infectious diseases [7], Basically, such models are based on a simple logic: when an infected individual $\alpha$ approaches to a healthy individual $\beta$, the healthy one has a given probability to shift into different possible states (i.e. become infected, become immediately immune, became immune after a certain time, etc ...). Nowadays, this models, born for predicting the result of the "physical interactions" are interesting for analysing the result of "digital interactions": an individual that have interaction with other individual can be neutral, or can be affected by its opinion and change the behaviour. Such concepts are interesting for many scopes and are often correlated to the "influence maximization problem" [8].

The WOM phenomena have been recognized from researcher and practices as one of the most influential source since the beginning of human society $[9,10]$ and nowadays, since people are constantly connected to the Web by smartphone such phenomena is exponentially amplified [11].

That's the reason why communication within social network is extremely powerful and the importance of the "propagation phenomena" is recognised in several disciplines; examples can be found in social science, politics, communication, marketing as well as homeland security with several keywords: "Digitalization of Word-of-mouth Phenomena", "Opinion Propagation", "Innovation Propagation", "Public Consensus Formathe behaviour of Complex Web Connected Systems and build a test environment.

\section{The potential of the open data for simulating large-scale agent-based intelligent social systems}

The work presented aims to extend the previous researches carried out from the authors for simulating individual behaviour in large-scale systems by means of Intelligent Agents. Indeed, Simulation Team, Genova University have several years of experience in reproducing Human Behaviour by means of Intelligent Agents Computer Generated Forces (IA-CGF) for simulating the dynamic evolution of different individual parameters like stress, fear, aggressiveness as result of social interactions [15]. These libraries have been fruitfully applied in urban disorders during country reconstruction [16], Disaster Management [17], homeland security [18], epidemic evolution [19] and Social influence in Obesity diffusion [20].

Modelling and Simulating Individual behaviour is really challenging: humans have several level of complexity: individual and social complexity. The Individual complexity is often driven by mental models that are not known and are partially hidden and irrational, while the Social Complexity is the result of the multitude of human interactions in the society [21]. In addition, Internet led to radical changes in the communication structure as well as in the social structure. This revolution can be compared to the invention of the press, and later, to the diffusion of the radio and the television. Nowadays interactions among people can happen not only physically and not only with one-direction instruments like television, radio and newspapers: now people can be also active in the process of information production. The results are complex, instant, frequent and bi/directional interactions among a complex network at worldwide scale [22]. 
In this context, agent-based social simulation (ABSS) can be helpful to capture the different phenomena inside a social network; indeed ABSS is often described as the intersection of three scientific areas [23]: Agentbased computing, Social sciences, and Computer simulation.

Obviously, simulating social systems requires a big amount of data for the Verification and Validation of the model and a new opportunity is given by the "open data". It is interesting to note that there is an increasing number Countries where "open data" are being placed on the political and administrative agenda [24, 25]. This results in an exponential growth of the quantity of "open information" available in several countries both from public and from private sources and it adds a new dimension to big data analytics giving rise to future data-driven innovation [26].

In this context, ABSS can provide many benefits: the first one is to offer the possibility to carry out experiments on artificial social systems that would be too costly and too complex for being carried out in real world. An additional advantage is the possibility to define simple social rules to smaller individuals and analyse the emergent complex behaviour of the whole system. Furthermore, it provides the possibility to capture the micro dynamics at individual level and its effects in the whole system; finally, artificial individuals can be created with missing data, by using partial knowledge of the system coupled with statistical estimation of the missing ones. In this way, the simulation is able create artificial data that can cover what is missing from the partial knowledge of the simulated system based on statistical estimations of the missing ones [27, 28].

\section{Method}

In order to capture the individual behaviour and its effect on the whole social community, the authors makes use of IA-CGF Libraries developed in the course of the year by Simulation Team (Figure 9) [6, 29]. The basic idea is to reproduce virtually an entire city in order to create a test environment for social dynamics based on the WOM phenomena. The authors have decided to use Genova City in Italy, a medium size city of 600.000 inhabitants for presenting a real test case since in order to reuse the IA-CGF libraries (Intelligent Agent-Computer Generated Forces) and NCF (Non-Conventional Framework) used on green product demand [5, 17].

The work presented aims to answer to the following questions:

- RQ1: How can we simulate in a quantitative way the changes in single Individual Opinion resulting from Social Interactions?

- RQ2: How can we use simulation for reproducing humans and measure social interactions (considering also that there are different types of interactions and stimuli: face-to-face, web interactions, television, radio, etc.)?

- RQ3: Is it possible to correlate daily individual activity and their probability to get social interactions?

- RQ4: Case study. How can we match an hypothetical Individual Opinion to the probability to buy Ethical Food vs Standard Food? How social interactions can affect such choice?

The answers to the following questions provided by the author are the following:

- ARQ1: We can define an "Individual Opinion Function" which can vary according to the different stimuli received during the day

- ARQ2: We can reproduce human behaviour by multi-layer Agent-Based simulation and we can estimate the social interaction based on individual activity

- ARQ3: Basically yes, we can assign a probability for an individual to get in touch with the other nodes of the network based on the activity that each individual is performing during the day and based on his social network structure

- ARQ4: We can define a choice model based on different parameters (i.e. income, age, sex, level of instruction, etc.), including the "Ethical Food Opinion Function"

\subsection{Multi-layer approach}

In the following, the authors propose a multi-layer approach for simulating a social system inside the city of Genova, (600,000 inhabitants). The simulation makes use of several sources of Open Data: Genova Municipality and Region Liguria, coupled with National, European and Worldwide Datasets.

The three main layers considered are the following Figure 1: 
- Layer 1: Entities and Objects

- Layer 2: Individual People

- Layer 3: Interest Group and Social Networks

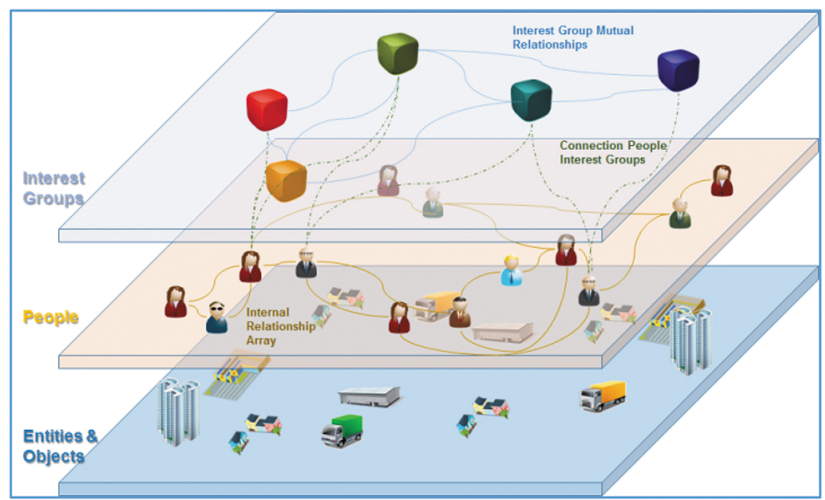

Figure 1: Multi-layer approach for simulating individual in daily activity.

\subsection{Layer 1: Entities \& objects}

This layer aims to represent all inanimate objects that are interesting for reproducing human behaviour activity in the form of Points of Interest. This approach allows to geo-localize punctual elements in a map and use these points as generators as well as attractors. This is the key for determining the daily individual behaviour of each single inhabitant moving around the town during the day. In the following table are reported the different categories that have been used for the simulation.

This layer includes ore that 1.000 points of interest have been inserted and geo-localized in the map. In addition, more than 3.000 of smallest point of interest have been created statistically based on urban density, and other economical indexes in order to reproduce a more realistic individual behaviour. In Table 1 are reported the 14 different categories of point of interest and their type. Indeed some activities like commercial centres as well as hospitals, police station ect.. are based on real data since are easily dentifiable, whereas other activities like bar small shops are simulation-generated based on different parameters (urban density, income etc..). Finally, the third cathegory are interest point partially based on real data as well as partially based on generated data (for example parking areas).

Table 1: Icons, point of interests and data sources.

\begin{tabular}{|c|c|c|c|c|c|}
\hline Points of interest & Icon & Type & Points of interest & Icon & Type \\
\hline Commercial Centres & & Based on real data & Cinema & 8 & Based on real data \\
\hline Hospital & & Based on real data & Theatre & & Based on real data \\
\hline Fire fighters & & Based on real data & Museums & & $\begin{array}{l}\text { Based on real } \\
\text { data/generated }\end{array}$ \\
\hline Police stations & & Based on real data & Bar & & Generated \\
\hline Small shops & & Generated & Households & & $\begin{array}{l}\text { Based on real } \\
\text { data/generated }\end{array}$ \\
\hline Parking areas & & $\begin{array}{l}\text { Based on real } \\
\text { data/Generated }\end{array}$ & Parks & & Based on real data \\
\hline Stadium & $\Leftrightarrow$ & Based on real data & Schools & & Based on real data \\
\hline
\end{tabular}

The whole Genova Municipality is subdivided into 71 statistical units which can be aggregated into the 9 Genova Municipalities that represent the smallest political unit and the smallest level of disaggregation of data available (Figure 2). 


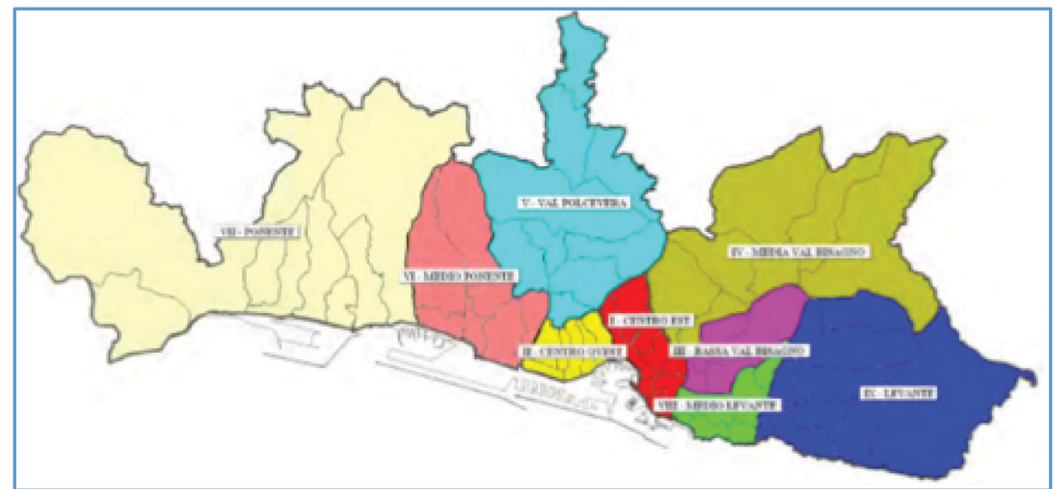

Figure 2: Genova political units.

\subsection{Layers 2 and 3: Ceneration of individual entities, families and interest groups}

In this second layer, people are created as single entities by using open data available. Hereafter is described the process for generating individual the simulation start. The simulator generates single individuals, at first, and then it aggregates each one into families and social network, based on a weighted graph in the following steps.
A. Individual Generation
B. Families and Interest Groups

Each individual is defined by the following parameters. These parameters are based on statistical analysis of the open data that have been analysed. The following are the nine parameters that have been considered for generating individual: Age, Sex, Level of Education, Area of the city where he lives, Area of the city where he works/go to school, Income, Occupation Type, Political Orientation, Ethnic Group, and Religion.

Once the individuals are generated (Figure 3), they are aggregated to other individuals by means of a compatibility algorithm to generate families and interest groups (Figure 4) [6].

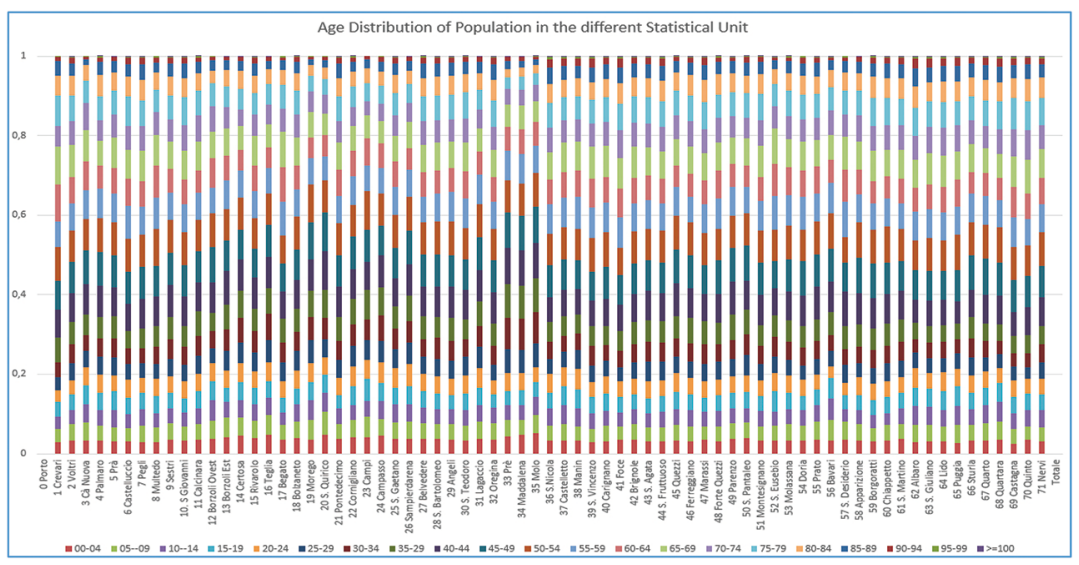

Figure 3: Age distribution in the statistical units.

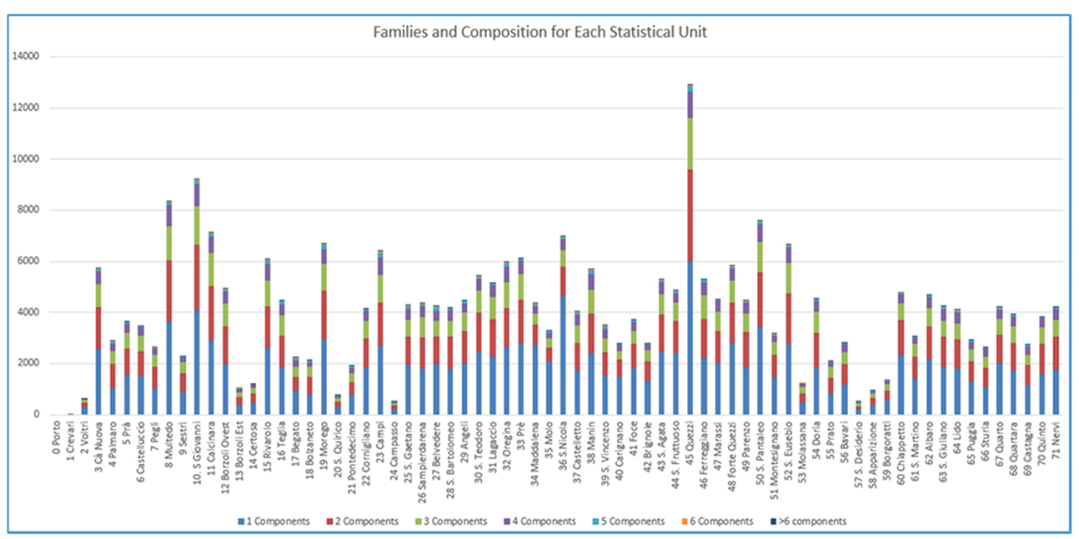


Figure 4: Families and their composition for each statistical unit.

\subsection{Generation of quasi-realistic social network}

One of the most effective ways to simulate social systems is by making use of graph theory and modelling the individuals by means of nodes and their connections by means of links. This layer aims to recreate single individual connections during the day. The basic idea is to use the social structure of each entity (friends, families, colleagues, etc.) and correlate it with the activities that each individual is performing during the day in order to estimate the probability to get in touch with other node of the network. To do so, it is necessary to define Nodes and links:

- Nodes: they represent Individuals, but also information sources (i.e. websites, and social networks) as well as standard information source like television, radio, etc.

- Links: they represent the connections among the different node of the network

In order to reproduce social interactions, we need to consider both face-to-face and virtual interactions; to do so, the author propose to make use of weighted connection in order to capture the different influence that each information source can have. In this way, an interaction with a family member is more powerful as compared to reading a post on a social network Figure 5. Such networks have been used firstly in system biology application and then adapted in large-scale social systems [30, 31].

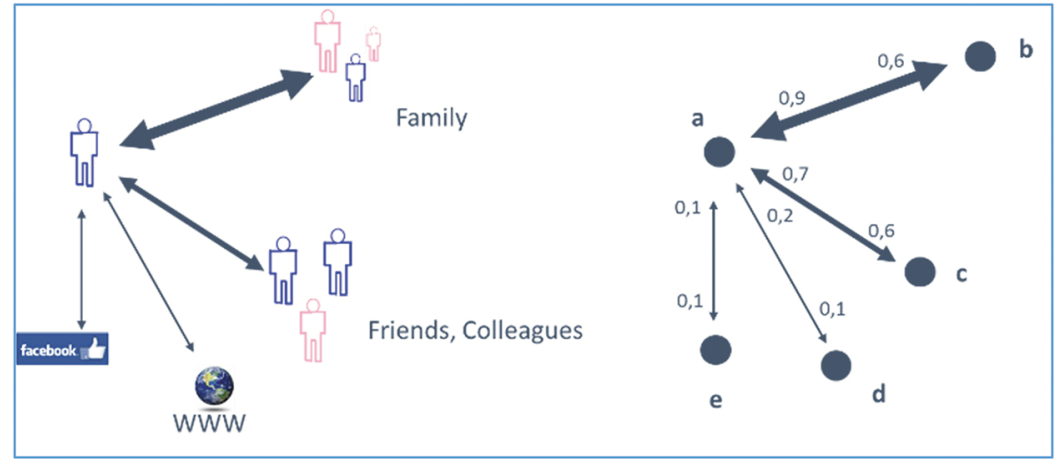

Figure 5: Weighted network for simulating influence in social interactions.

\subsection{Calculation of daily activities and O/D matrix calculation}

At this step, each single people according to the parameters that have been considered have an assigned a set of activities that are performed daily. Table 2 shows an example of the activities on a "standard week" for a generic individual.

Table 2: Example of parameters used for generating individuals.

\begin{tabular}{lll}
\hline ID $=\mathbf{2 2 3 , 5 1 2}$ & Parameters & Value \\
\hline Individual parameters & Age & $25-30$ \\
& Sex & M \\
& Level of education & Middle school \\
& Living statistical unit & 65 \\
& Working statistical & 43 \\
& Occupation type & White collar \\
& Income & $\$ 25,000$ \\
Connected to the WEB & Religion & Catholics \\
Family parameters & Politic orientation & Neutral \\
& Yes & $100 \%$ \\
\hline
\end{tabular}

${ }^{1}$ Individual Daily Activity Cycle 


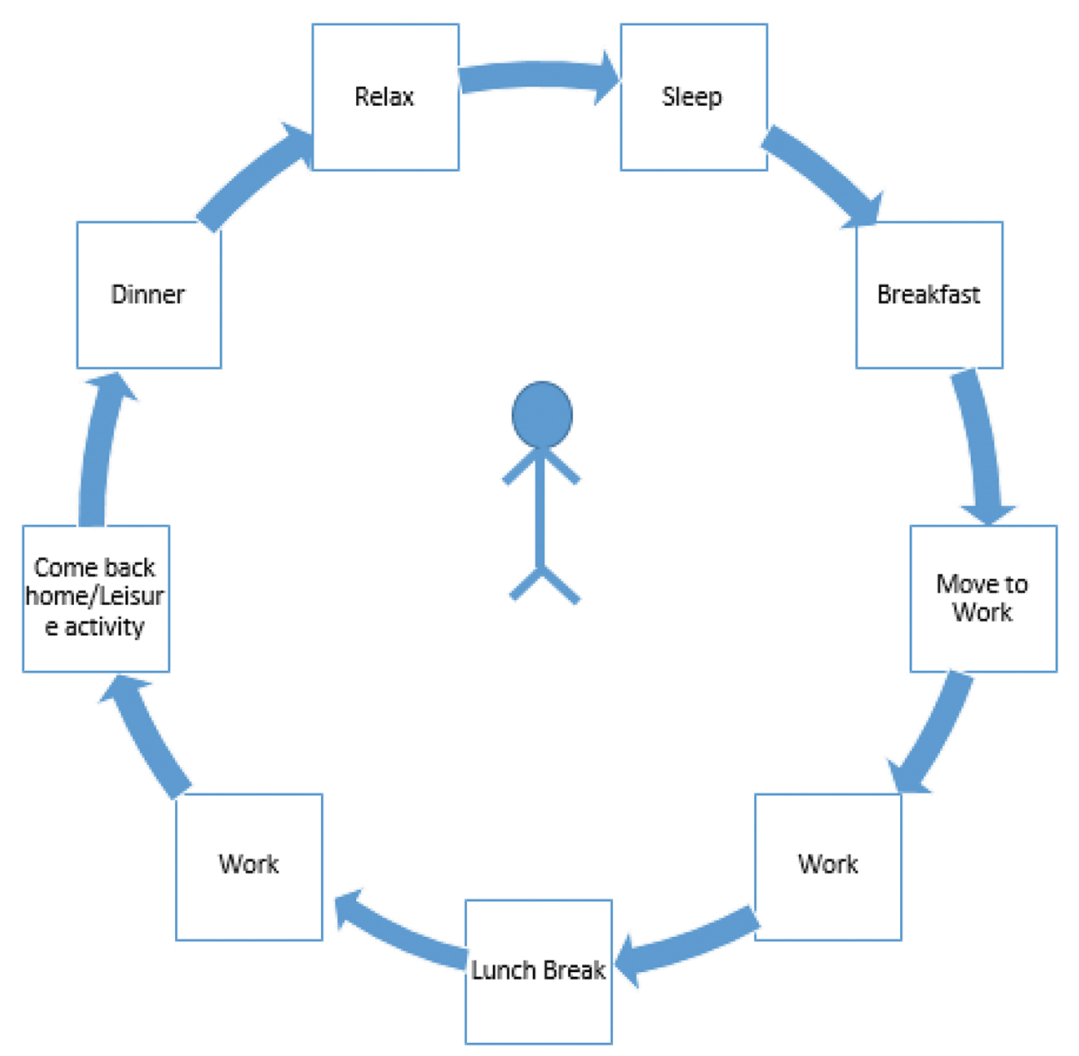

Daily activity based on the figure above is used for calculating people movement around the city during the simulated time in terms of $\mathrm{O} / \mathrm{D}$ Matrix. The simulator is equipped also by a transport choice model witch allow to reproduce the main segments of rail and transport network in the city. Each individual choses the best path my maximizing its utility considering the different attributes (i.e. car owner or not).

By this approach, the population is simulated as composition of single intelligent individuals living in the simulated town. Each agent is characterized by an intelligent behaviour that makes him moving inside the town and perform activities (i.e. buy food, go to work, go to school, drive, move in the free time, etc.). Figure 6 depicts the distribution of the different entities in the different zones of the city, while Figure 7 shows the car traffic flow over the network in the morning peak hour resulting from simulation run.

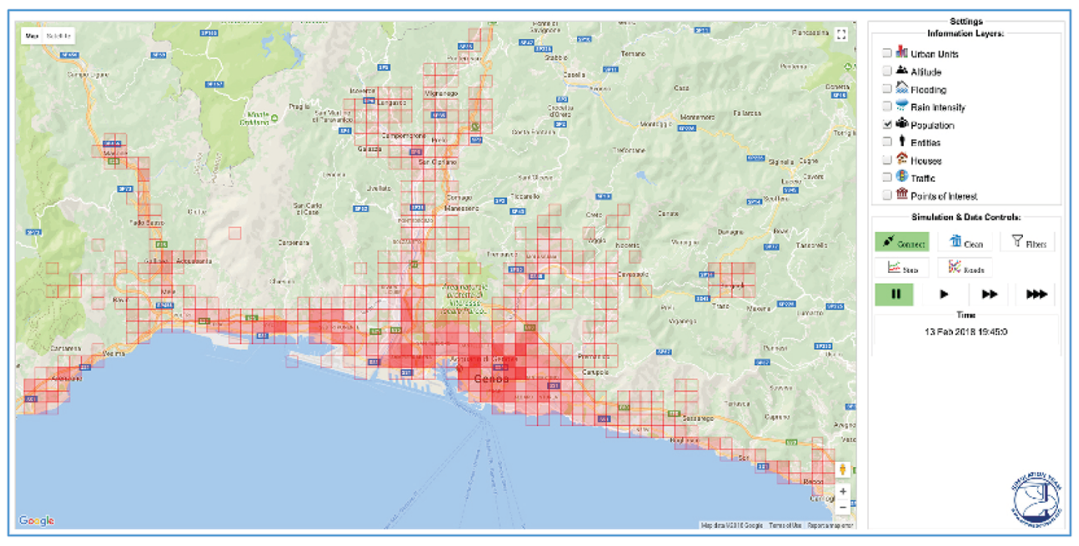

Figure 6: Distribution of the different entities in the different zones of the city.

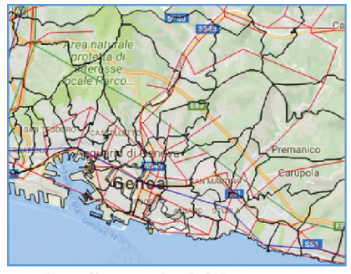

Car flows h 6,00 a.m.

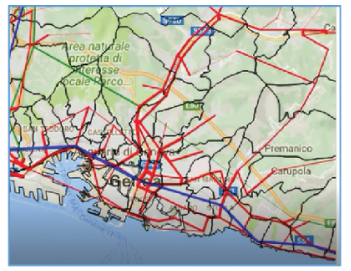

Car flows h 9,15 a.m.

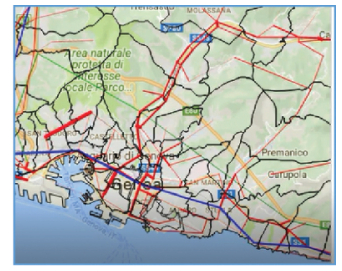

Car flows h 9,45 a.m.

Figure 7: Car traffic flow resulting from the simulation. 


\subsection{Simulating social interactions and opinion dynamics}

Modelling Social Interactions and Opinion Dynamic requires several assumptions and definitions; for the purpose of this paper, the author makes the following ones:

\subsubsection{Structure of the network}

Social networks can be depicted as a directed graph where:

- The nodes: represent single individuals and standard communication channels (i.e. Television and Radio)

- The links: represent interaction between two nodes

$$
G=G(\mathrm{E}, \mathrm{V}, \mathrm{t})
$$

The set $\mathrm{V}$ of vertices of the graph is fixed, while the set $\mathrm{E}$ of edges can change in time $t$ according to simulation results (1). This graph reproduces the interactions in time between the different nodes.

\subsubsection{Interactions}

The model proposed by the authors considers three type of interactions: $\alpha, \beta, \gamma$, where

- $\alpha=$ Physical Interactions: when two agent meets physically one each other

- $\beta=$ Standard Communication Interactions: when an agent watch television, listen the radio

$-\gamma=$ Web Interactions: when two agents get in contact by Internet (i.e. reading post, blogs, tweets, etc.)

In addition, it is also necessary to distinguish:

- One way interactions $(\beta)$ : Television and Radio are considered one-way relationship since the other user cannot influence the content of suck media

- Two way interactions $(\alpha, \gamma)$ : Individuals can influence one each other

\subsubsection{Individual opinion function}

In the following, a possible opinion function for each individual is presented: Opinion Function of i-individual $O_{i}$ is assumed to be a time dependent function that can vary when the i-individual get in contact with individual opinion form another entity $O_{j}$ :

$$
\begin{aligned}
& O_{i}(\mathfrak{t})=O_{i}(t+1)+\alpha_{i} * \Delta O(t)_{i, j} \\
& O_{j}(\mathfrak{t})=O_{j}(t+1)+\alpha_{j} * \Delta O(t)_{j, i}
\end{aligned}
$$

where (4) represents the opinion difference between two entities:

$$
\Delta O_{i, j}=O_{i}-O_{j}
$$

$\alpha_{i}:[0: 1]$ inertia coefficient, it determine how strong is the individual opinion when faces other opinion

$O_{i}$ : can assume the following integer values : $[-10: 10]$ with:

- $O_{i}=0$ neutral

$-O_{i}=10$ strongly agree

$-O_{i}=-10$ strongly disagree 
In order to build a simple model for a first test case, the following assumptions have been made:

a. The content of the information exchange between two connected node is mono-thematic

b. When two individuals get in contact they mutually exchange the opinion: $O_{i}$ influences $O_{j}$ and $O_{j}$ influences $\mathrm{O}_{i}$ in the same proportion

c. Internet penetration: in order to define what are the individual that are connected to the network by means of a smartphone all individual $>13$ years and $<70$ year are assumed to own a smartphone which allow to access to web social network

d. Connections between the nodes are determined by the Connection Matrix $C(t)$ that is computed by the simulator. Such matrix is updated during each time step with the following rule:

a. If $(i, j)>0$ then individual $i$ is connected to individual $j$

b. If $I, j=0$ then individual $i$ is not connected to individual $j$

e. Each individual can be connected to only one node for each time step

f. Connections are instantaneous: when two entities are in connections, they exchange their opinions immediately

Matrix $C(t)$ is the result of the daily individual activity of each entity; more precisely, each i-individual during his day has an assigned probability to get in touch with other agents according to his daily routine. For example, if he is driving he will have more probability to listen the radio compared to the probability to read a post. Such matric include both face-to-face and web interaction in a whole single matrix and its evolution stochastically driven.

\section{Case study: Simulating word of mouth and ethical food choices}

Here in the following, a case study for matching the previous urban simulator with a Food Choice model is presented. The choice between standard food and greed food is assumed to be dependent on three parameters: price, accessibility and "Ethical Opinion" resulting from the WOM calculated by the simulator. In Table 3 are reported the weght coefficient used for the different interactions. For the sake of this experiment 8 different type of interactions have been considered: Family member, Friends, Colleagues, Other Individuals, Facebook, Radio. Other social Network and Television. As it is possible to note, a family member or a friend is considered much more influencing of a radio advertising or television. It is interesting to note, (Figure 8) that Interactions can be: one-way (i.e. radio, television and other standard communication sources as well as two-ways (i.e. social networks).

Table 3: Weight assigned for each type of connection.

\begin{tabular}{lllllll}
\hline $\begin{array}{l}\text { Family } \\
\text { member }\end{array}$ & Friends & $\begin{array}{c}\text { Colleagues Other } \\
\text { individuals }\end{array}$ & Facebook & Radio & $\begin{array}{l}\text { Other social } \\
\text { networks }\end{array}$ & \begin{tabular}{c} 
Television \\
\hline 0.9
\end{tabular} \\
\hline
\end{tabular}

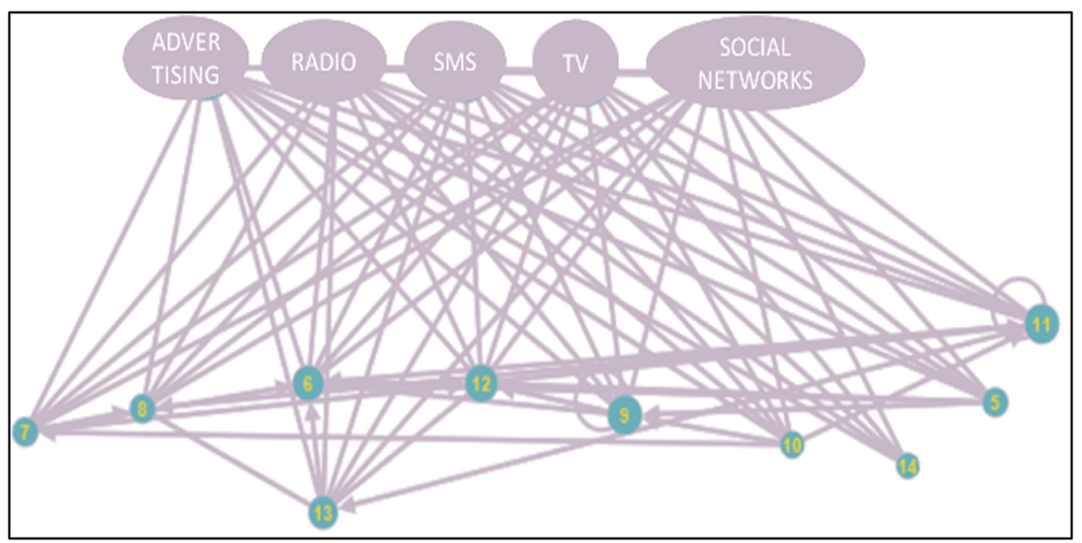


Figure 8: Social network structure.

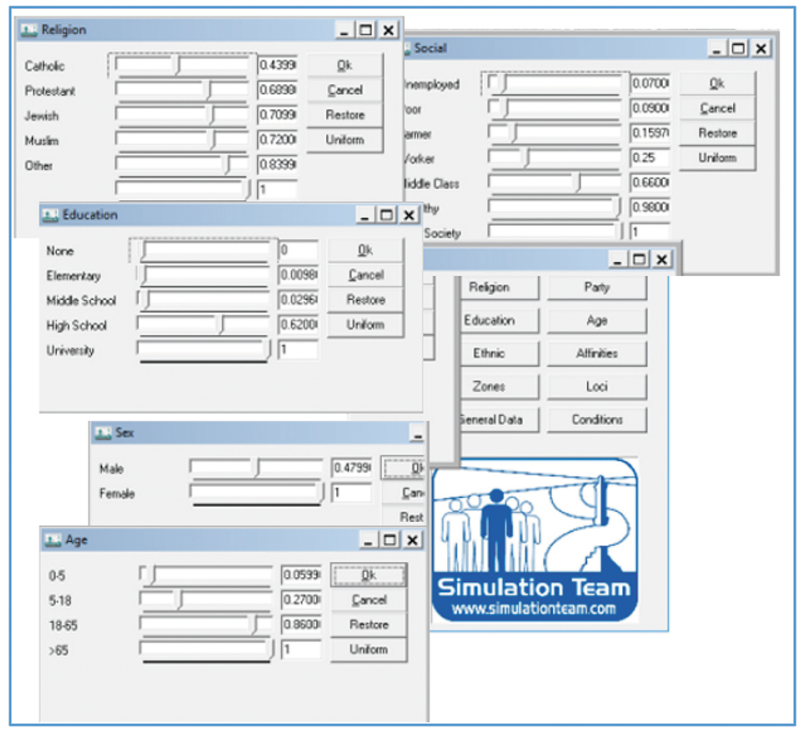

Figure 9: IA-CGF individual people characteristics.

\subsection{Motivation}

Many hypotheses exist about the modern drivers of consumer demand and the growing influence of ethical and environmental issues since over 20 years [32-35]; indeed, the food industry is even further sensitive to these elements and there are interests in investigating these aspects to develop new models [36]. The complexity of this context touches many different issues, from operational ones (e.g. logistics and production processes) to marketing and promotion often dealing with human factors [37-39]. It is evident that the complexity of each of these elements and their mutual interactions with human factors create many challenges in the development of quantitative analysis on this framework. Therefore, the importance to create models and simulators dealing with these issues results to be a strategic advantage for planner and decision-makers [40-42]. Due to these reasons, the authors propose an agent-based simulation able to capture how consumers affect and are affected from an opinion inside the communication network. Several authors dealt with the WOM phenomena and the factors affecting consumer's choices: for example [43], investigated the gender differences on brand loyalty, while [44], investigated how WOM can influence consumers' decision-making and attitude formation. This research was based on three main parameters: tie strength, homophily (in terms of composition in terms of the similarity of members' characteristics), and source credibility. Attitude formation have also been studied for elaborating social media strategies and techniques to preserve corporate reputation after a damaging event which spread negative information over the social network in form of tweets considering three different categories of tweets: pro, neutral and against.

\subsection{Ethical and food consumption}

Hereafter, different researchers and models, developed along the years, are summarized in order to identify the most promising approaches to be used in a modern simulation tool for simulating food consumption choices based on the correlation of different factors, and perform further analysis. These empirical findings raise a question for investigation "what are the key parameters affecting food choice and how WOM can be reproduced in a simulator for a quantitative analysis?". Simulating WOM is really challenging since it affect both individual and social layer; several authors have underline how individual Ethic affect, also indirectly, consumer psychology and individual food choices [45-47].

\subsubsection{First two main drivers: Price and accessibility}

Despite the widespread attention in ethical consumption is receiving, consumers show little interests in actually purchasing ethical products, such as organic or fair-trade produces. For instance, Futerra [48] found that whilst 
$30 \%$ of consumers claims themselves to be ethical consumers whereas only $3 \%$ of them actually put into practices. Such intention-behaviour gap reflects the situation that the benefit of product ethicality is at a lower hand against the practical concerns, such as price, accessibility, and quality issues, in the decision-making process [49].

\subsubsection{Third driver: Social network position}

Yet, there is increasing evidence suggesting impression management reasons as main key factors to promote ethical consumption. For instance, Griskevicius, Tybur, and Van den Bergh [50], demonstrated that eliciting consumers' status motives increase their desire for green products. The use of social norms (e.g. joining fellow citizens to save waters) increase also the likelihood for pro-social choices [51,52]. Extent researches demonstrate these lay beliefs drive, unconsciously, people's ethical product choices. For instance, Griskevicius et al. [50] demonstrated that by motivating consumers attaining a high social status, the likelihood for them to choose green products over the regular counterparts increases as the former helps signal a positive social image.

Consumer's social network position is defined as the relationship between himself/herself and other individuals or groups within the network. In terms of analysing the consumer's network position involves two main types of centrality in this research. The first of which is betweenness centrality that is defined as the least number of times that an actor needs to take in order to approach another agent [53]. More precisely, betweenness centrality captures the extent to which an actor facilitates the information flow within the network, not sheer number of connections he/she possess. Consequentially, when a high betweenness-centrality actor leaves the network, the efficiency of the network itself suffers in terms of information flow [54]. The second type is the closeness centrality which is defined as the number of connections that a person possesses. Consequentially, when a consumer is in a high degree of betweenness and/or closeness centrality position, he, or she, will be involved in frequent social interactions in everyday life. Such situation requires a person to present a positive image in front of others, so that the authors argue that these types of consumers have a high need for impression management in their everyday life [55]. Impression management, corresponding to maintaining a good image in front of others, is found as a key factor that motivates consumer's ethical product choices. This pattern reflects the instrumental altruism facet in people's altruistic behaviour $[56,57]$. More specifically, purchasing an ethical product, though implicitly, signals the buyer a positive pro-social or moral image [58, 61]. Such symbols, in people's beliefs, would have positive effects on people's social life, such as being reckoned as a trustworthy member of the group.

Based upon an instrumental altruism perspective, the authors conjecture is that consumer's social network position (e.g. how many connections they have and how central and active they are in the network) affects to what extent they will appreciate the social values of ethical products [56,57]. Firstly, people who are at the central positions within their social network generally play as the roles of opinion leaders or lead users, which involve them having frequent social interactions with other members within their social node [54]. Therefore, these types of consumers would have a higher need for impression management whereas the engagement in ethical consumption results to be one of major means that consumers do frequently [62]. In fact, agent-based modelling has been applied in different area of marking to capture the aggregate dynamics originated from interactions among individual consumer $[63,64]$ as well as to examine these impacts on consumer's choice [65]. Based on such insights, the authors decided to focus the attention on three parameters affecting the food choice: Price, Accessibility and closeness centrality that is implicitly calculated by the simulator in terms of probability of $i$ node to get in touch with $j$ node.

\subsection{Human behaviour modelling applied to ethical consumption and closeness centrality}

Here the authors focus their attention in simulating the changes in individual Opinion Function in the form of "Ethical Value" in order to capture the ethical food choice VS the standard food one. The following weight have been assigned for determine the influence in "Ethical Value". In this first experiment, such parameters have been supposed to be the same for all the individuals, but the simulator have the capability to assign one single parameter for each individual. All these parameters are assumed in both the direction, from a generic node to individual $i$ and from individual $i$ to the generic node $j$. 


\subsection{From ethical value function to a mode choice}

In this step, the author aim to link the Ethical Value to the food choice; Discrete Choice Models are useful to analyse and predict the individual choices when the set of choice is constituted by a finite number of alternatives. Random Utility Model (RUM) have been proposed for the first time by [66]; these disaggregate models have been widely used for the simulation of individual choices in particular for what concern transportation and travel choices [67]; choices are based on a finite number of transport alternatives such as start a trip or not, choose the departure time, choose the mode of transport, and choose the route. Each individual has a set of different choices that depend on personal parameters, for example: age, income, availability of a private car, individual value of time, type of the trip. For an extensive description of these models is possible to take in account interesting previous models developed in this field since decades $[67,68]$.

Considering the consumer choice, such models have been widely applied, also considering the Behavioural Decision Theory (BDT) [69]. In general, discrete choice model Discrete are derived from utility theory and in this case is applied a simple binary Logit is applied [70]; the common requirements for discrete choice models are as follows:

- The set of alternatives must be collectively exhaustive; this implies that each individual and groups of similar individuals have its own set of alternatives from where to choose

- The alternatives must be mutually exclusive

- The set must contain a finite number of alternatives

Each individual is expected to maximise its $u t i l i t y$ derived from the different options that are available among the possible choices in set $C$. In this case, each individual $i$ has option among 2 choices:

$a$ : Standard Food

$b$ : Ethical Food

Each of these options provides to the single individual the $u$ tility from the two options: $U_{a}$ and $U_{b}$ with:

$$
\begin{aligned}
& U_{a}=V_{a}+\varepsilon \\
& U_{b}=V_{b}+\varepsilon
\end{aligned}
$$

$V_{n}=$ Systematic Utility of each n-option

$\varepsilon=$ Error Term (Assumed to have a logistic distribution) for simulating the error on perception of each single individual and irrational behaviour.

Therefore, the probability of choosing an alternative $n$ for each individual $i$ is given by

$$
P_{i, n}=\mathrm{G}\left(x_{i, a}, x_{i, b} \underset{*}{\underset{i}{\gamma},} \beta_{i}\right)
$$

$x_{i, a}$ is a vector of attribute of alternative $a$

$x_{i, b}$ is a vector of attribute of alternative $b$

$\gamma_{*}$, is a vector of characteristic of person $i$

$\beta_{i}[0: 1]$ is a parameters

$$
\begin{gathered}
U_{i, n}=V_{i, n}+\varepsilon \\
V_{i, n}=\beta_{i, n} * \gamma_{i, n}
\end{gathered}
$$

So, the probability of choosing a green product $a$, and/or a standard product $b$, for each individual $i$ is defined by

$$
\begin{gathered}
P_{a, i}=\operatorname{Pr}\left(-V_{a, i}+\varepsilon_{a, i}\right)>\operatorname{Pr}\left(-V_{b, i}+\varepsilon_{b, i}\right) \\
P_{b, 1}=\operatorname{Pr}\left(-V_{a, i}+\varepsilon_{a, i}\right)<\operatorname{Pr}\left(-V_{b, i}+\varepsilon_{b, i}\right)
\end{gathered}
$$




$$
\begin{aligned}
& P_{a, i}=\frac{1}{1+\exp \left(-\beta_{i} \cdot V_{a, i}\right)} \\
& P_{b, i}=\frac{1}{1+\exp \left(-\beta_{i} \cdot V_{b, i}\right)}
\end{aligned}
$$

For modelling customer green choices, the authors have considered the following additional parameters that have been correlated to each single individual.

$U_{i, a}=\beta_{1} *($ Green - Standard Product Cost $)+\beta_{2} *$ Ethical Value of individual $\mathrm{i}+\beta_{3} *$ (Accessibility of the Ethical Shops)

$U_{i, b}=\beta_{1} *($ Green - Standard Product Cost $)+\beta_{2} *$ Ethical Value of individual $\mathrm{i}+\beta_{3} *$ (Accessibility of the Standard Shops)

These parameters have been hypothesized considering specific assumptions and the choice manipulation is based on the following parameter:

- Price sensitiveness (Ethical food and Standard Food) [71]

- Ethical Value Function

- Accessibility of the ethical food based on the daily minimum distance from ethical shop in individual routine

\subsection{Simulation results}

For this first experiment have been performed a simulation with real data from the city of Genova, in particular have been considered 71 zones and 600,000 Individuals. Each individual has been defined by its own parameters generated stochastically based on aggregated open data available from Genoa databases. A first simulation run was performed with one month of simulated time

Obviously, a very critical aspect in developing this model is to finalize the VV\&A (Verification, Validation and Accreditation) processes. Due to these reasons the author are actually conducting dynamic virtual experimental campaigns on numerical case to achieve preliminary validation of the proposed approach; ANOVA technique and experimental error temporal evolution analysis are the methods to be used to check consistency of the stochastic factors included in the models [72].

\subsection{Practical implication of the research to existing literature}

This paper proposes a preliminary investigation devoted to match intelligent agents with the simulation of the WOM phenomena within the social network, with a case study on ethical food product consumption based on the propagation of an individual opinion.

The contribution of this paper is the following: firstly, it presents a multi-layer approach for simulating humans and their activities within a complex urban environment with the use of open data. Secondly, it proposes to define a green value function in order to estimate propagation phenomena and its effect on food choice. Finally, it proves the potential of $M \& S$ approach for supporting marketing scientist in testing and validating their hypothesis within a synthetic environment.

\section{Conclusions}

The complexity of the WOM phenomena as well as the uncertainty affecting the human factors is evident, as well as the efforts required to fine-tuning the model parameters. Therefore, it is important to outline that the adopting of agent driven simulation enables to model complex scenarios and could result an interesting instrument for building a test environment.

As anticipated, the authors are working on VV\&A and are finalizing the numerical data sets for the proposed scenario based on examples inspired by real historical case studies; these data will be used to complete dynamic and statistical VV\&A of the proposed simulator by using also the support of subject-matter experts. 


\section{References}

[1] Manyika ], Lund S, Bughin ], Woetzel JR, Stamenov K, Dhingra D. Digital globalization: the new era of global flows. San Francisco: McKinsey Clobal Institute, 2016

[2] CSMA. The Mobile Economy 2018. 2018.

[3] Perrin A. Social media usage: 2005-2015. 2015.

[4] Meeker M. Internet trends 2015-code conference. Glokalde. 2015;1:3.

[5] Bruzzone AC, Agresta M, Agresta M, Hsu JH. Human behavior and social influence: an application for green product consumption diffusion. Proc.of WAMS, Florence, September 2017.

[6] Bruzzone A, Massei M, Longo F, Poggi S, Agresta M, Bartolucci C, et al. Human behavior simulation for complex scenarios based on intelligent agents. In: Proceedings of the 2014 Annual simulation symposium. Society for computer simulation international, 2014:10.

[7] Teng PS. A comparison of simulation approaches to epidemic modeling. Annu Rev Phytopathol. 1985;23:351-79.

[8] Mossel E, Roch S. On the submodularity of influence in social networks. In: Proceedings of the thirty-ninth annual ACM symposium on Theory of computing. ACM. 2007:128-34.

[9] Katz E, Lazarsfeld PF. Personal influence. Clencoe, IL: Free Press, 1955.

[10] Coleman ]S. Medical innovation: a diffusion study. Indianapolis, IN: Bobbs-Merrill, 1966.

[11] Barreto AM. The word-of-mouth phenomenon in the social media era. Int ] Market Res. 2014;56:631-54.

[12] Liu CY, Hu XF, Si CY, Luo P. Public opinion propagation model based on small world networks. ] Syst Simul. 2006;12:3608-10.

[13] Dellarocas C. The digitization of word of mouth: promise and challenges of online feedback mechanisms. Manage Sci. $2003 ; 49: 1407-24$.

[14] Watts D], Dodds PS. Influentials, networks, and public opinion formation. J Consum Res. 2007;34:441-58.

[15] Bruzzone AC, Massei M. Intelligent agents for modelling country reconstruction operation. Pro Third IASTED African Conf. 2010;685:34.

[16] Bruzzone AG, Tremori A, Massei M. Adding smart to the mix. Modeling simulation \& training. Int Defense Train ]. 2011a;3:25-7.

[17] Bruzzone AC, Massei M, Agresta M, Murino G. A decision support system for disaster prevention in Urban Areas. In: Proc. of. 4th International workshop on simulation for energy, sustainable development and environment, SESDE, 2016.

[18] Bruzzone AG, Massei M, Longo F, Nicoletti L, Di Matteo R, Maglione G, et al. Intelligent agents \& interoperable simulation for strategic decision making on multicoalition joint operations. In: Proc. of the 5th International Defense and Homeland Security Simulation Workshop, DHSS, Bergeggi, Italy, 2015.

[19] Bruzzone AG, Novak V, Madeo F. Obesity epidemics modelling by using intelligent agents. SCS M\&S Mag. 2012a;9:18-24.

[20] Bruzzone AG, Novak V, Madeo F. Agent based simulation model for obesity epidemic analysis. In: Proceedings of I3M2012. Austria: Wien, 2012b.

[21] Woods DD. Coping with complexity: the psychology of human behaviour in complex systems. Tasks, errors, and mental models. Bristol, PA, USA: Taylor \& Francis, Inc, 1988:128-48.

[22] Christian F. Internet and society. Social theory in the information age. New York: Routledge, 2008. Routledge Research in Information Technology and Society Series Number 8. ISBN 0415961327. 408 Pages.

[23] Davidsson P. Agent based social simulation: A computer science view. JASSS. 2002;5:1.

[24] Bauer F, Kaltenböck M. Linked open data: the essentials. Vienna: Edition mono/monochrom, 2011.

[25] Huijboom N, Van Den Broek T. Open data: an international comparison of strategies. Eur ] ePract. 2011;12:4-16.

[26] Manyika ], Chui M, Groves P, Farrell D, Van Kuiken S, Doshi EA. Open data: unlocking innovation and performance with liquid information. Washington, DC: McKinsey Clobal Institute, 2013.

[27] Richiardi M, Leombruni R, Saam N, Sonnessa M. A common protocol for agent-based social simulation, Journal of Artificial Societies and Social Simulation ed. 2006.

[28] Davidsson P. Multi agent based simulation: beyond social simulation. In: International Workshop on Multi-Agent Systems and AgentBased Simulation. Springer, Berlin, Heidelberg, 2000:97-107.

[29] Bruzzone AG, Tremori A, Tarone F, Madeo F. Intelligent agents driving computer generated forces for simulating human behaviour in urban riots. Int ] Simul Process Model. 2011b;6:308-16.

[30] Can F, Özyer T, Polat F, editors. State of the art applications of social network analysis, Lecture Notes in Social Network ed. Springer, 2014.

[31] Bruzzone AC. Intelligent agent-based simulation for supporting operational planning in country reconstruction. Int ] Simul Process Model. 2013;8:145-59.

[32] Crane A. Unpacking the ethical product. ] Bus Ethics. 2001;30:361-73.

[33] Moisander ]. Motivational complexity of green consumerism. Int ] Consum Stud. 2007;31:404-9.

[34] Strong C. Features contributing to the growth of ethical consumerism-a preliminary investigation. Mark Intell Plann. 1996;14:5-13.

[35] Peloza ], White K, Shang ]. Cood and guilt-free: the role of self-accountability in influencing preferences for products with ethical attributes. J Mark. 2013;77:104-19.

[36] Jensen KD, Denver S, Zanoli R. Actual and potential development of consumer demand on the organic food market in Europe. N]ASWageningen ] Life Sci. 2011;58:79-84.

[37] Schröder M], McEachern MC. Consumer value conflicts surrounding ethical food purchase decisions: a focus on animal welfare. Int ] Consum Stud. 2004:28:168-77.

[38] Bruzzone A, Massei M, Bocca E. Fresh-food supply chain. In: Merkuryev Y, Merkuryeva G, Piera MA, Guasch Petit A. editor. Simulationbased case studies in logistics. London: Springer, 2009:127-46.

[39] Siro I, Kápolna E, Kápolna B, Lugasi A. Functional food. Product development, marketing and consumer acceptance-A review. Appetite. 2008;51:456-67.

[40] Bruzzone AG, Tremori A, Massei M, Tarone F. Modeling green logistics. In: Proceedings of AMS, Third IEEE Asia International Conference on Modelling \& Simulation, May 2009b:543-8. 
[41] Vermeir I, Verbeke W. Sustainable food consumption: exploring the consumer "attitude-behavioral intention" gap. ] Agric Environ Ethics. 2006;19:169-94.

[42] Bredahl L, Grunert KC, Frewer L]. Consumer attitudes and decision-making with regard to genetically engineered food products-a review of the literature and a presentation of models for future research. J Consum Policy. 1998;21:251-77.

[43] Rialti R, Zollo L, Pellegrini MM, Ciappei C. Exploring the antecedents of brand loyalty and electronic word of mouth in social-mediabased brand communities: do gender differences matter?] Global Mark. 2017;30:147-60.

[44] Brown ], Broderick A], Lee N. Word of mouth communication within online communities: conceptualizing the online social network. ] Interact Mark. 2007;21:2-20.

[45] Michaelidou N, Hassan LM. The role of health consciousness, food safety concern and ethical identity on attitudes and intentions towards organic food. Int ] Consum Stud. 2008;32:163-70.

[46] Zollo L, Yoon S, Rialti R, Ciappei C. Ethical consumption and consumers' decision making: the role of moral intuition. Manage Decis. 2018;56:692-710.

[47] Shaw D, Newholm T. Voluntary simplicity and the ethics of consumption. Psychol Mark. 2002;19:167-85.

[48] Futerra SCL. The rules of the game: the principals of climate change communication. London, UK: Depart- ment for Environment, Food and Rural Affairs, 2005.

[49] Devinney TM, Auger P, Eckhardt CM. The myth of the ethical consumer. Cambridge: Cambridge University Press, 2010.

[50] Criskevicius V, Tybur ]M, Van Den Bergh B. Coing green to be seen: status, reputation, and conspicuous conservation. ] Pers Soc Psychol. 2010;98:392-404.

[51] Coldstein N], Cialdini RB, Griskevicius V. A room with a viewpoint: using social norms to motivate environmental conservation in hotels. ] Consum Res. 2008;35:472-82.

[52] White K, Simpson B. When do (and don't) normative appeals influence sustainable consumer behaviors?] Mark. 2013;77:78-95. DOI: 10.1509/jm.11.0278.

[53] Freeman III, AM. Benefits of environmental improvement: theory and practice. Baltimore: John Hopking Uniiversity Press, 1979.

[54] Kratzer ], Lettl C. Distinctive roles of lead users and opinion leaders in the social networks of schoolchildren. ] Consum Res. 2009;36:64659.

[55] Goffman E. Interaction ritual: essays on face-to-face behavior. Chicago: Aldine, 1967.

[56] Andreoni ]. Impure altruism and donations to public goods: a theory of warm-glow giving. Econ ]. 1990;100:464-77.

[57] Kahneman D, Knetsch ]L. Valuing public goods: the purchase of moral satisfaction. ] Environ Econ Manage. 1992;22:57-70.

[58] Semmann D, Krambeck H], Milinski M. Reputation is valuable within and outside one's own social group. Behav Ecol Sociobiol. 2005:57:611-16.

[59] Catlin JR, Wang Y. Recycling gone bad: when the option to recycle increases resource consumption. ] Consum Psychol. 2013;23:122-7. DOI: 10.1016/j.jcps.2012.04.001.

[60] Wedekind C, Braithwaite VA. The long-term benefits of human generosity in indirect reciprocity. Curr Biol. 2002;12:1012-5.

[61] Mazar N, Zhong C-B. Do green products make us better people? Psychol Sci. 2010;21:494-8.

[62] Crane A, Matten D. Business ethics: managing corporate citizenship and sustainability in the age of globalization. OUP Oxford: Oxford University Press, 2016. ISBN : 9780199564330.

[63] Coldenberg ], Libai B, Muller E. Using complex systems analysis to advance marketing theory development: modeling heterogeneity effects on new product growth through stochastic cellular automata. Acad Mark Sci Rev. 2001;2001:1.

[64] Delre SA, Broekhuizen TL, Bijmolt TH. The effects of shared consumption on product life cycles and advertising effectiveness: the case of the motion picture market. ] Mark Res. 2016;53:608-27. DOI: 10.1509/jmr.14.0097.

[65] Haenlein M, Libai B. Targeting revenue leaders for a new product. ] Mark. 2013;77:65-80.

[66] Block HD, Marschak ]. Random orderings and stochastic theories of responses. Contrib Probab Stat. 1960;2:97-132.

[67] Hall K, Ben-Akiva ME, Lerman SR. Discrete choice analysis: theory and application to travel demand, vol. 9. Massachusetts: MIT Press, 1985:7-38.

[68] Ben-Akiva M, Bierlaire M. Discrete choice models with applications to departure time and route choice the handbook of transportation science, 2nd ed. Massachusetts, 2003. (eds.) R.W.

[69] Swait ], Adamowicz W. Choice environment, market complexity, and consumer behavior: a theoretical and empirical approach for incorporating decision complexity into models of consumer choice. Organ Behav Hum Decis Process. 2001;86:141-67.

[70] Matejka F, McKay A. Rational inattention to discrete choices: A new foundation for the multinomial logit model. Am Econ Rev. 2014:105:272-98.

[71] Lichtenstein DR, Ridgway NM, Netemeyer RG. Price perceptions and consumer shopping behavior: a field study. ] Mark Res. 1993;30:234245.

[72] Montgomery DC. Design and analysis of experiments. John wiley \& sons, 2017. 